\title{
Wide-angle $X$-ray scattering studies on contemporary and ancient bast fibres used in textiles - ultrastructural studies on stinging nettle
}

\author{
Mira Viljanen $(\mathbb{D} \cdot$ Jenni A. Suomela $\cdot$ Kirsi Svedström
}

Received: 10 February 2021 / Accepted: 22 December 2021 / Published online: 24 January 2022

(C) The Author(s) 2022

\begin{abstract}
Stinging nettle (Urtica dioica) is a potential source material for industrial applications. However, systematic research on the ultrastructural properties of nettle fibres is lacking. Determining the ultrastructure of nettle and the other bast fibres also provides new insights into the studies of archaeological fibres and their usage. In this study, the nanostructure of modern and ancient nettle samples was studied using wide-angle X-ray scattering (WAXS) and compared to other bast fibres. The culturohistorical fibre samples consisted of nettle, flax, and hemp from White Karelian textiles collected 1894 as well as of 800-900-year-old archaeological textile fragments from Ravattula Ristimäki burial site, Finland. Using WAXS, the average cellulose crystallite widths, relative crystallinities and orientational order (including microfibril angle for the modern fibres)
\end{abstract}

were determined and compared. The results also revealed the suitability of the WAXS analysis for fibre identification. The crystallite widths were of the similar size for all modern fibres $(3.4-4.8 \mathrm{~nm})$. Subtle differences in the relative crystallinities in descending order (from flax to nettle, and finally hemp) were observed. Also, subtle differences in the mean MFAs were observed $\left(10 \pm 1^{\circ}\right.$ for flax, $12 \pm 1^{\circ}$ for nettle, and $14 \pm 1^{\circ}$ for hemp). For the culturo-historical fibres, the values for crystallite widths and relative crystallinities were larger compared to the corresponding modern references. In addition, features due to the presence of non-cellulosic, crystalline substances (e.g., calcium oxalates) were detected in the WAXS patterns of all the modern nettle fibres. These features could potentially be used as a tool for identification purposes.

Supplementary Information The online version contains supplementary material available at https://doi.org/10.1007/ s10570-021-04400-w.

M. Viljanen $(\bowtie) \cdot$ K. Svedström

Department of Physics, University of Helsinki, Gustaf

Hällströmin katu 2, P.O. Box 64, 00014 Helsinki, Finland

e-mail: mira.viljanen@helsinki.fi

\section{J. A. Suomela}

Department of Education/Craft Studies, University of

Helsinki, Siltavuorenpenger 10, P.O. Box 8,

00014 Helsinki, Finland 


\section{Graphical abstract}
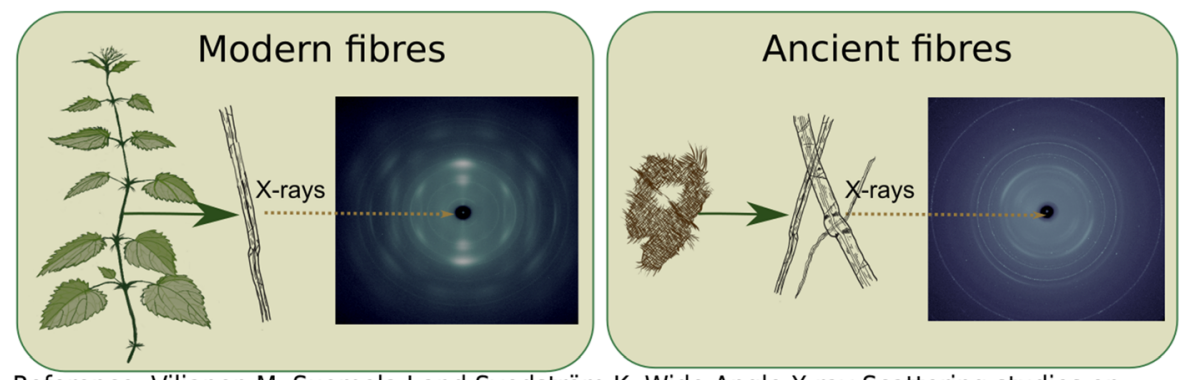

Reference: Viljanen M, Suomela J and Svedström K. Wide-Angle X-ray Scattering studies on contemporary and ancient bast fibres used in textiles -ultrastructural studies on stinging nettle. Cellulose, 2022. Visual Abstract by Mira Viljanen

Keywords Nettle $\cdot$ Plant fibre $\cdot$ Ultrastructure Wide-angle X-ray scattering

\section{Introduction}

Plant fibres have been used in clothing, tools, and decorations since the early days of human history, due to their accessibility, processability, and great mechanical properties. The most common plant fibres used in textile making in the Northern Hemisphere were flax (Linum usitatissimum), hemp (Cannabis sativa) and stinging nettle (Urtica dioica). Perhaps one of the most important fibres for craftmanship has been stinging nettle (Geijer 1979). Stinging nettle is believed to be used as textile fibre before the arrival of the cultivated plant fibres (Riikonen 2011). Even today, with our greater than ever increasing need for sustainable and durable textile-making materials, nettle-derived fibres could potentially prove to be promising candidates for such purposes. In order to pursue this, the ultrastructural properties of nettle fibres need to be studied in more detail.

Nettle fibres, like flax and hemp, are derived from the plant stem (bast fibres), consisting of elongated, dead sclerenchyma cells. These cells function as the supportive tissue of the plant, due to their cell wall structure and thickness (Sfiligoj et al. 2013). Inside the cell walls, the cellulose chains are accumulated into partially crystalline microfibrils, embedded into a hemicellulose-lignin matrix. The properties and orientation of the microfibrils are significant, as they affect the strength and stiffness of the whole plant (Reiterer et al. 1999).
The cellulose microfibrils are helically oriented around the cell lumen, forming a specific angle with the vertical axis of the cell, known as the microfibril angle. In a primary cell wall, the orientation of the microfibrils is random, in contrast with the secondary cell walls, in which the microfibrils are highly orientated within each of three sublayers. The whole fibre is said to be orientated with a Z-twist if the microfibrils in the thickest sublayer of the secondary cell wall twist to the right, while the opposite case (a left-handed twist) of fibrillar orientation is known as a S-twist. A modified Herzog test or a red plate test is utilised to determine the twist direction (S- or Z-twist) (Haugan and Holst 2013).

Stinging nettle belongs to the family of Urticaceae, as does the more widely studied ramie (Boehmeria nivea). Nettle is a wide-spread plant in the wild, requiring almost no extra watering or care, thus making it an excellent biodegradable source for fibre production (Markova 2019). This ecological aspect combined with other advantageous traits such as its nontoxicity, processability and ability to be recycled, have contributed to the popularity and increasing utilization of nettle fibres and yarn products (Debnath 2015). Nowadays, the interest in plant fibres and fibreformed structures is not only limited to textiles as some common plant fibres have turned out to be very functional materials for biocomposites due to their useful mechanical properties (Ramamoorthy et al. 2015). Alongside other well-studied plant fibres (Sanjay et al. 2019), nettle has been increasingly researched to determine its suitability to be used as a composite material (Kumar and Das 2017b; Viju and Thilagavathi 2020). 
Regarding the history of textile making, it has recently been suggested that nettle textiles were used more broadly and commonly in the past than has been previously assumed (Bergfjord et al. 2012; Vajanto 2014; Suomela et al. 2018, 2020). In fibre research, nettle fibres have often been overlooked in favour of flax and hemp, leading to a false identification of the fibres and incorrect assumptions about the plants used in crafts. The identification of bast fibres (flax, nettle and hemp) is still challenging with existing methodologies, even though the urge to produce more reliable results comes from various fields ranging from archaeology to criminology (Deedrick 2000).

From the archaeological point of view, even single fibres or their physical traces can provide useful information about a cultural context. Textile fibre finds can all potentially contribute to the knowledge of the materials, techniques, and skills required to make an item, as well as to past social environments, the migration patterns of the inhabitants, and ancient trade routes (Good 2001).

The fibrillar orientation (S- or Z-twist) is one of the key features of interest when it comes to identifying bast fibres from both modern and archaeological textiles. For plant fibre identification studies, commonly used techniques include transmission light microscopy (TLM) and polarized light microscopy (PLM), which are used to observe the surface characteristics and other distinctive properties of the fibres. In addition, the cross-sectional characteristics of the fibres (Suomela et al. 2018) and traces of single mineral crystals or crystal clusters (druses) in the fibre-associated tissue (Bergfjord and Holst, 2010) are also studied. These crystals and druses are mainly compounds of calcium-derived oxalates and carbonates, formed into a specific crystallographic structure (Fengel and Wegener 1983; Webb 1999), and are observable in PML, depending on their sizes and the resolution of the equipment used. In addition, these crystals and clusters can be studied further using scanning electron microscopy (SEM) (Markova 2019) and plasma-ashing (Jakes and Mitchell 1996).

One example of a type of fibre identification study that benefits from combining all of the abovementioned fibre features is the case of separating flax and nettle fibres: they share the same fibrillar orientation (Bergfjord and Holst 2010), but have different and distinctive cross-sectional shapes (Nayak et al. 2012; Suomela et al. 2018; Lanzilao et al. 2016).
Additionally, it has been reported that oxalate crystals and clusters have not been detected in flax fibres (Catling and Grayson 1982; Bergfjord and Holst 2010).

The traditional TML and PLM measurements, which are limited to the micrometer resolution, that have been conducted on fibre samples do not provide information about the ultrastructural properties, i.e. the structures of the cellulose microfibrils. By conducting X-ray Diffraction (XRD) and scattering measurements on fibre samples, it is possible to obtain information on the atomic and nanoscale arrangement of the cellulose. XRD and Wide-Angle X-ray Scattering (WAXS) can be used to determine the amount of crystalline cellulose in the total weight of the sample and the size and orientation of the cellulose crystallites in the cellulose microfibrils. By comparing the ultrastructural properties of the cellulose microfibrils, it is possible to characterize the condition of the cellulose in the fibre samples (Müller et al. 2007).

$\mathrm{X}$-ray scattering and diffraction methods are widely used to study the nanoscale properties of cellulosebased materials, because they are considered to be non-destructive, i.e. the methods do not often require any chemical treatment or sectioning of the samples. From the archaeological point of view, such nondestructive research methods that only require a very small amount of sample are highly desirable. X-ray scattering and diffraction techniques are relatively unused but promising methods that can be applied on the structural studies of archaeological and modern fibres (Müller et al. 2004, 2006, 2007).

In this study, various modern and historical samples of stinging nettle, flax, hemp, and cotton were studied using WAXS and traditional microscopy methods (PLM \& TLM). The aim of the research was to gain information about the structural properties of the cellulose microfibrils in nettle bast fibres, in contrast to the better-studied species (flax, hemp, cotton). It should be noted that there are only a few previous home laboratory XRD studies conducted on archaeologic fibres (Chen et al. 1998). In addition, only a small number of studies have focused on the structural properties of pure nettle textile fibres (Bergfjord and Holst 2010; Bergfjord et al. 2012; Kumar and Das 2017a; Lanzilao et al. 2016), and no systematic research specifically on the ultrastructural characteristics of cellulose microfibrils in nettle in comparison with the other well-studied fibrous species has 
previously been made. Thus, this research provides novel ultrastructural information, both regarding the structural properties of stinging nettle and the cellulose structure state of the unique archaeological and historical bast fibres included in this study.

\section{Materials}

For the study, different types of modern (reference) and culturo-historical (ethnographic and archaeological) bast fibre samples were measured using WAXS. The ethnographic samples were classified as nettle, flax or hemp based on the previously published TLM and PLM results (Suomela et al. 2020). In addition, three archaeological fibre samples were measured using WAXS to be used as a comparative result, as well as to test the method's practicality to study degraded samples. The TLM/PLM results of these archaeological fibres are published in a separate article (Suomela et al. 2022).

The studied reference samples belonged to species and subspecies of stinging nettle, hemp, and flax (Table S1 in supplementary). These reference samples have been classified by the location of the fibres in the plant (root/stem/crown), by the collection date and by the method used to detach the fibres. These methods simulated traditional practices for removing fibres from surrounding plant tissues. Some fibres were detached from dried stems, and some were waterretted in a bucket. Different detachment methods were applied to see whether they had any influence on the structure or characteristics of the fibres.

The culturo-historical samples consisted of ethnographic and archaeological samples from two separate sources. The ethnographic samples are from the Finno-Ugric Collection SU4522 of the National Museum of Finland. The samples were extracted from linen textiles collected in 1894 from the White Karelian region, Russia, and have been stored in stable museum conditions since. These textiles represent the materials from the eighteenth and nineteenth century, and are presented in detail in Suomela et al., 2020. Details of the samples can also be found in the supplementary material in Table S2.

The archaeological samples consisted of small textile fragments, excavated from a burial ground located in Ravattula Ristimäki in Kaarina, Finland. Ravattula Ristimäki was an active excavation site
(2010 to 2016) of the Department of Archaeology of the University of Turku. The site consists of a semiChristian and Christian inhumation cemetery with the oldest known Christian church in Finland. The burial ground has been determined to have been in use from approximately the 12th century to the early 13th century. As an archaeological period, this timeline falls towards the end of the local Crusade period (Ruohonen 2017).

Before any of the studies, the samples were stored in Eppendorf-tubes at room temperature and normal moisture conditions.

All of the studied archaeological samples were found in different graves, and within proximity of possible bronze and silver-containing items, i.e. the sheath of a knife (sample TYA 912:523D) and a bracelet (sample TYA 914:1607:8A). A third sample was found from the upper body area of the deceased, in close contact with a glass bead and next to a silver coin (sample TYA 933:214:9:50).

\section{Methods}

Optical microscopy measurements

In this study, the microstructural characteristics of the selected ethnographic samples representing each bast fibre type (nettle, hemp, flax), as well as the differences between them, were illustrated using TLM and PLM.

All of the ethnographic fibre samples were identified in a previous study (Suomela et al. 2020) using the three-stage procedure introduced and explained in detail by Suomela et al. (2018). The procedure includes an observation of the longitudinal and cross-sectional characteristics with TLM and a determination of the microfibrillar orientation with a Modified Herzog test using PLM. Based on these results, the samples were identified as either originating from nettle, hemp, flax, or cotton, with the fibre type noted in Table 1 and Table S2 (supplementary).

WAXS measurements and analysis

The orientational order, mean microfibril angle (MFA), average width of the cellulose crystallites, and the relative fraction of the crystalline cellulose (relative crystallinity) of fibre samples were studied 
Table 1 The average crystallite widths, relative crystallinities, and orientation parameter (OP) obtained from the modern fibres and ethnographic fibres, extracted from the White Karelian textiles*

\begin{tabular}{|c|c|c|c|c|c|}
\hline Sample & Fibre type & Crystal width[nm] $\pm 0.2 \mathrm{~nm}$ & Relative crystallinity $(\%) \pm 5 \%$ & $\operatorname{MFA}\left(^{\circ}\right) \pm 1^{\circ}$ & $\mathrm{OP} \pm 0.09$ \\
\hline Root A & Flax & 4.6 & 37 & 12 & 0.71 \\
\hline Crown A & Flax & 4.5 & 34 & 8 & 0.68 \\
\hline Stem B & Flax & 4.1 & 36 & 11 & 0.69 \\
\hline Root C & Nettle & 3.7 & 34 & 19 & 0.69 \\
\hline Stem C & Nettle & 4 & 33 & 12 & 0.68 \\
\hline Crown $\mathrm{C}$ & Nettle & 3.4 & 39 & 8 & 0.7 \\
\hline Stem D & Nettle & 3.9 & 33 & 11 & 0.66 \\
\hline Root E & Nettle hyb & 3.7 & 32 & 12 & 0.72 \\
\hline Stem E & Nettle hyb & 3.6 & 32 & 12 & 0.68 \\
\hline Crown $\mathrm{E}$ & Nettle hyb & 3.6 & 31 & 12 & 0.77 \\
\hline Stem F & Nettle hyb & 3.6 & 28 & 15 & 0.72 \\
\hline Root G & Hemp & 4.4 & 24 & 13 & 0.62 \\
\hline Root H & Hemp & 3.9 & 29 & 14 & 0.55 \\
\hline Root I & Hemp & 3.7 & 33 & 14 & 0.55 \\
\hline Stem J & Hemp & 4.8 & 29 & 14 & 0.66 \\
\hline Sample $2 \mathrm{a}^{*}$ & Nettle & 5.3 & 68 & & 0.88 \\
\hline Sample 5a* & Flax & 7 & 62 & & 0.7 \\
\hline Sample $9 b^{*}$ & Nettle & 6.9 & 68 & & 0.52 \\
\hline Sample $48 \mathrm{~b} *$ & Flax & 6.3 & 53 & & 0.47 \\
\hline Sample $49 a^{*}$ & Flax & 6 & 50 & & 0.66 \\
\hline Sample $73 \mathrm{ba}^{*}$ & Hemp & 6.5 & 51 & & 0.54 \\
\hline Sample $85 \mathrm{~d}^{*}$ & Nettle & 6 & 48 & & 0.48 \\
\hline
\end{tabular}

*(Suomela et al. 2020). The mean microfibril angle (MFA) values were determined for the modern fibres alone

using wide-angle $\mathrm{x}$-ray scattering (WAXS). The WAXS measurements were conducted in the X-ray laboratory at the University of Helsinki using a custom-built measurement setup with perpendicular transmission geometry mode. The X-rays were produced by a conventional copper $\mathrm{x}$-ray tube, powered by a generator (Seifert) using a current and voltage of $25 \mathrm{~mA}$ and $36 \mathrm{kV}$, respectively. A Montel multilayer monochromator (Incoatec) was used to select the corresponding $\mathrm{Cu} \mathrm{K} \alpha$ radiation $(\lambda=1.541 \AA$ ), and the scattered intensities were collected onto a MAR345 2D image plate detector (Marresearch).

A sample of lanthanum hexaboride $\left(\mathrm{LaB}_{6}\right)$ was used to calibrate the scattering angle $2 \theta$-range and to obtain the value of the instrumental broadening, which was determined to be approximately $0.3^{\circ}$.

The samples were measured dry, either in the open air or when placed between two mylar foils in a washer. The measurement time was $42-60 \mathrm{~min}$ per sample due to the extremely small amount of the sample material.

The WAXS data was analysed using Matlab. The data was corrected for background scattering arising from the air and mylar foils by subtracting the background, which was measured by using an empty sample holder covered with two mylar foils. The absorption, geometrical, and polarization corrections were applied to the data. The transmission values for absorption correction, which was conducted before the background subtraction, were determined from the primary beam by using a semi-transparent copper beam stop.

The data was integrated using a $50^{\circ}$-wide sector (for crystallite width analysis) and a $180^{\circ}$-wide sector (for relative crystallinity analysis) around the cellulose 200 reflection in the two-dimensional scattering pattern. From the integrated data, the average width of the cellulose crystallites (crystallite size) and the relative 
amount of crystalline cellulose (crystallinity) in the samples were determined.

For the microfibril angle analysis of the modern fibres, an azimuthal integration over a $180^{\circ}$-wide sector around the cellulose 200 reflection was carried out in a similar way to that described in (Sarén et al. 2004). It must be noted here, that using the azimuthal profile for a complete fibre sample (i.e., signal arising from both the front and rear walls), it is not possible to determine whether the fibre has a Z- or S- twist, as the microfibrils are helically wound around the cells. In addition, for the modern and ethnographic fibres, the level of anisotropy was studied by computing the orientational order parameter $(O P)$ (Kuczyński et al. 2002). The $O P$ value was determined using the azimuthal intensity distribution of the cellulose 200 reflection and the contribution of the constant, i.e. fully isotropic background was neglected. The $O P$ value was not computed for the archaeological fibres because they showed WAXS patterns of fabrics; thus, the comparison of the $O P$ values would not be feasible for them.

The average crystallite size was obtained using the Scherrer equation (the shape factor $K$ being 0.9) and a similar curve-fitting method as described in detail in (Svedström et al. 2012). The curve fitting method takes into account the 4 main cellulose reflections around the 200 peak, which in this dataset corresponds to the $2 \theta$-range from $12^{\circ}$ to $28^{\circ}$. Due to the extremely low scattering intensity acquired for the sample TYA 912, the average crystallite width has been computed by approximating the FWHM of the 200 reflection (without Gaussian fitting) and using the Scherrer equation.

For the modern and ethnographic bast fibre samples, the relative crystallinity was determined using the amorphous fitting method reported in full detail in (Ahvenainen et al. 2016). The scattering contribution from the amorphous components of the cell wall was taken into account by using an amorphous standard, measured from sulphate-lignin (Andersson et al. 2003). In the case of the modern samples of nettle and hemp, 19 Gaussian peaks were used in the curve fitting process while for the rest of the fibre samples (excluding the Ravattula TYA 912 sample), 18 Gaussians were used, based on the cellulose $\mathrm{I} \beta$ structure determined by (Nishiyama et al. 2002). The list of the used cellulose reflections is given in Table S3. It must be noted that there are several possibilities for the peak shape (e.g. pseudo-Voigt function) (Wada et al. 1997). The Gaussian shape of the peak was justified in our case based on the calibration sample measurements and the previous work carried out with various cellulose samples (Ahvenainen et al. 2016).

\section{Results}

Results of the microscope studies on the microstructure of bast fibres

Here we present examples of the microscale structures often found in the studied fibres of flax, hemp, and nettle. The presented examples are unpublished TML and PML images of the White Karelian fibres, and complementary information can be found in (Suomela et al. 2020). Due to large number of samples, crosssectioning was conducted by using paper glue as mounting media which decreases the quality of the images.

Regarding the ethnographic flax fibres (Sample 5a, Fig. 1a), sparse cross markings and narrow lumen were detected. Cross-sectional observations were done using table glue method (Suomela et al. 2020). The characteristic polygonal structure and small lumens typical for flax fibres could be detected in the images (Fig. 1b). We also used a modified Herzog test to study the fibrillar orientation, which revealed a twist in the S-direction (Fig. $1 \mathrm{c}^{1}$ and $\mathrm{c}^{2}$ ). Due to the set up in the microscope, the index colours of blue and yellow (Figs. 1, 2, and 3) appear the opposite than given in standard SFS-EN ISO 20706-1:2019.

In the longitudinal observation of nettle fibres (Sample 9b, Fig. 2a), typical cross-markings and dislocations were observed. It was possible to detect kidney-shaped structures with flat lumens in the crosssection images (Fig. 2b). Using a modified Herzog test, colour features similar to those observed in flax fibres were detected, thus the fibrillar orientation was determined to be $\mathrm{S}$ (Fig. $2 \mathrm{c}^{1}$ and $\mathrm{c}^{2}$ ).

The only ethnographic hemp sample, 73ba, had typical cross-markings and dislocations for bast fibres (Fig. 3a). Circular shaped large lumens were visible in the cross-sectional image (Fig. 3b), however polygonal and kidney-shaped forms were also detected. Nevertheless, in case the of hemp, the identification can be grounded on the modified Herzog test which 


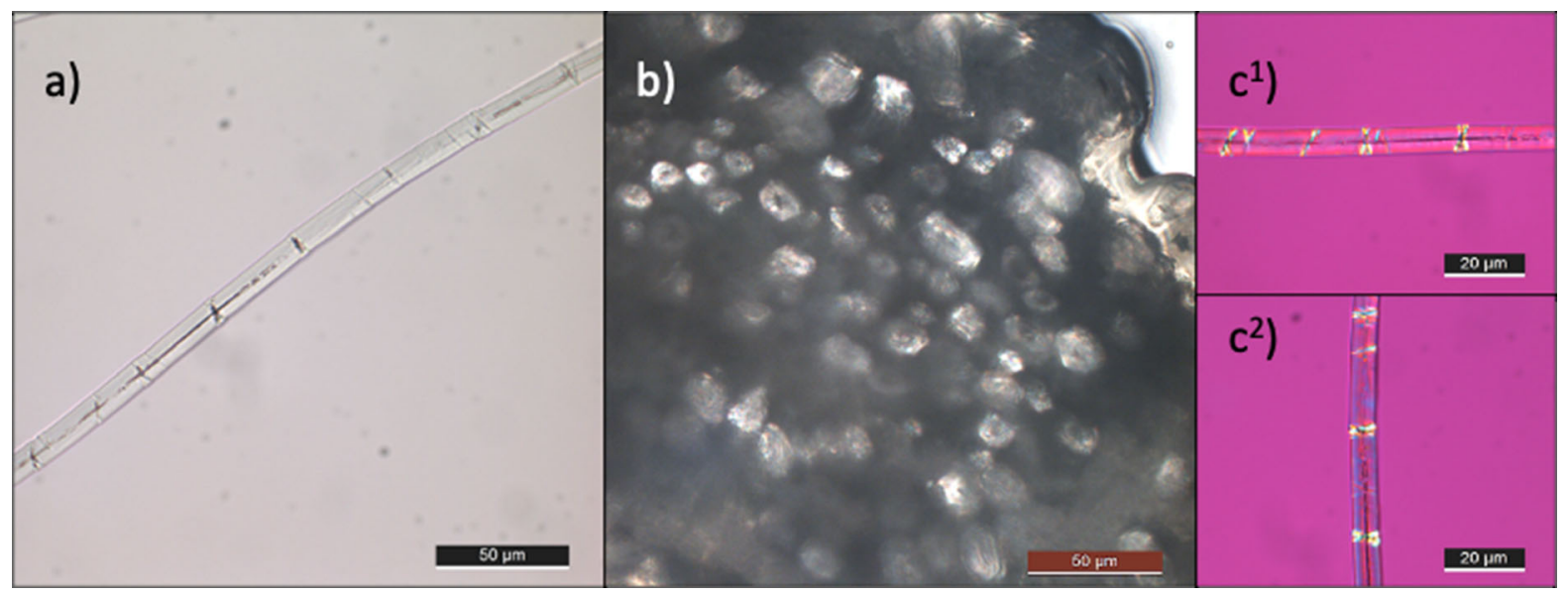

Fig. 1 TLM and PLM images of the White Karelian flax fibre 5a

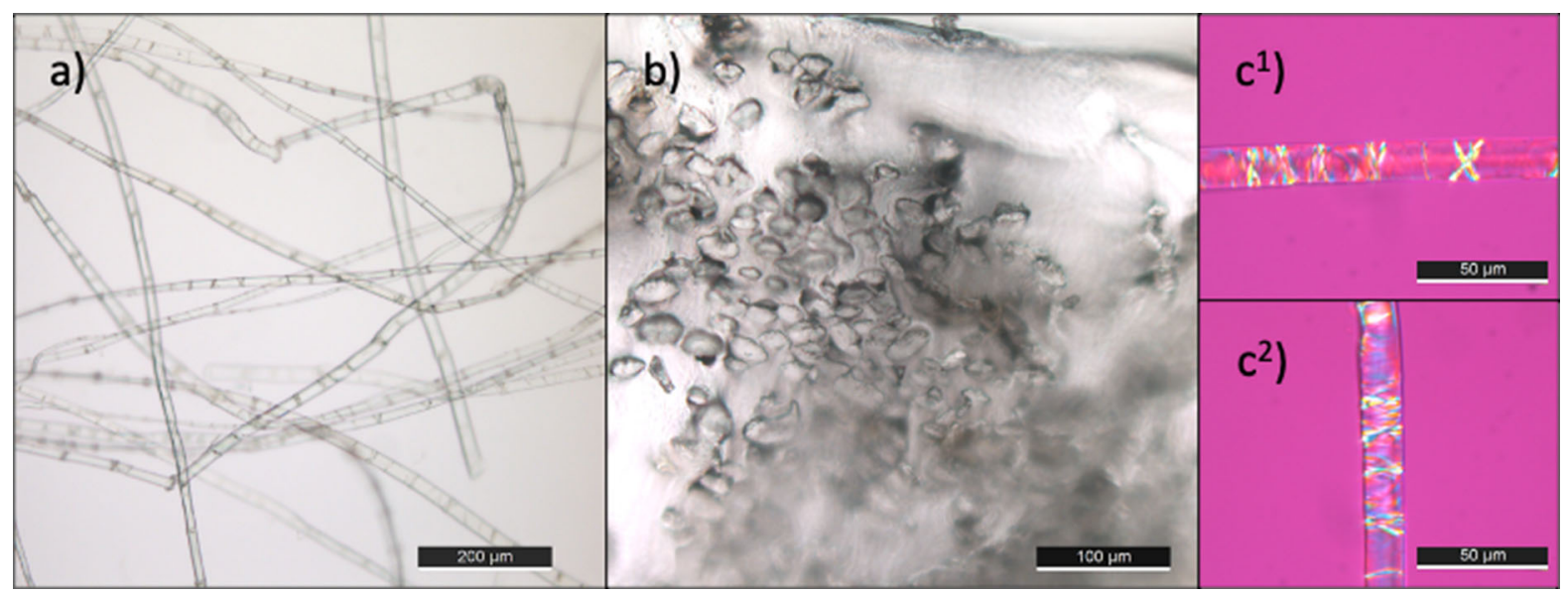

Fig. 2 TLM and PLM images of the White Karelian nettle fibre 9b


Fig. 3 TLM and PLM images of the White Karelian hemp fibre 73ba 
clearly shows an opposite twist to that of flax and nettle (Fig. $3 \mathrm{c}^{1}$ and $\mathrm{c}^{2}$ ).

\section{WAXS results}

We studied the cellulose crystallite widths, relative amount of crystalline cellulose, and the orientational order parameter (and mean microfibril angle in the case of modern fibres) of the fibre samples using laboratory X-ray scattering equipment. The size of $\mathrm{X}$-ray beam used was $1 \mathrm{~mm}$. The size of the measured fibres varied from 1-mm-thick clusters (reference samples) and microscopical pieces of fabric weaves (archaeological samples) down to a minimum of $100-\mu \mathrm{m}$-thick bundles (ethnographical samples): the measured parameters are average values across the whole sample (considering the beam size, a corresponding area within the sample is covered). The acquired parameters of interest for each studied sample are presented in Table 1 (modern fibres \& ethnographic fibres), and Table 2 (archaeological fibres). For the ethnographic cotton samples, the acquired values for crystallite widths can be found in Table S4 (supplementary).

\section{The modern (reference) fibres}

For the modern fibres, the obtained average crystallite widths ranged from $3.4 \mathrm{~nm}$ to $4.8 \mathrm{~nm}$, with the accuracy of the results being $0.2 \mathrm{~nm}$. On the average, the obtained crystallite width was smallest in the nettle samples (range 3.4-4.0 nm) compared to the values obtained for flax and hemp (range 4.1-4.6 and $3.7-4.8 \mathrm{~nm}$, respectively).

The relative crystallinity values obtained for modern fibres were all between 24 and 34\% ( $\pm 5 \%$-units), showing an ascending order from hemp (24-33\%) to

Table 2 The obtained average crystallite widths obtained for the archaeological fibre samples from Ristimäki in Ravattula

\begin{tabular}{lc}
\hline Sample & Crystal width[nm] \\
\hline TYA 912:523D & $6.1 \pm 0.5 \mathrm{~nm}$ \\
TYA 933:214:9:50 & $7 \pm 0.2 \mathrm{~nm}$ \\
TYA 914:1607:8A & $5.6 \pm 0.2 \mathrm{~nm}$ \\
\hline
\end{tabular}

For clarification reasons, the samples are referred to in descending order as Ravattula TYA 912, Ravattula TYA 933, and Ravattula TYA 914 within the text nettle (28-34\%), and finally to flax, with the highest acquired crystallinity values (34-37\%). Examples of the WAXS patterns and crystallinity fits of the modern fibre samples are presented in Fig. 4 (Nettle), S1 (Hemp), and S2 (Flax).

In the case of the microfibril angles, small mean MFA values for all species and samples were detected. The acquired mean MFA values for nettle samples ranged from $8^{\circ}$ to $19^{\circ}$, and for flax samples from $8^{\circ}$ to $12^{\circ}$. In the case of hemp, the obtained MFA values were similar or slightly higher, the mean being around $14^{\circ}$. Also based on the lower OP values, the hemp fibres were slightly more isotropic than flax and nettle fibres.

In addition to the WAXS pattern of cellulose, in the 2D scattering images of the modern nettle and hemp fibres, bright diffraction spots with high relative intensities were detected. The possible origin and significance of these observations is covered in the Discussion section below.

\section{The ethnographic (White Karelian textile) fibres}

For the White Karelian fibres of flax, nettle, and hemp, the average crystallite widths ranged from 5.3 to $7 \mathrm{~nm}$ (Table 1). For the cotton fibre samples from the same collection, the average crystallite width ranged from 6.4 to $7.8 \mathrm{~nm}$ (Table S4).

The relative crystallinity values of the cellulose in the ethnographic fibres of flax, nettle, and hemp were determined to be between 48 and $68 \%$. An example of the crystallinity fit, along with the $2 \mathrm{D}$ scattering image for a garment nettle fibre, is presented in Fig. 5.

\section{The archaeological (Ravattula Ristimäki) fibres}

For all of the Ravattula archaeological samples, the main reflections of cellulose I $\beta(110,1-10,200,004)$ were observed in the WAXS patterns (Nishiyama et al. 2002), thus verifying the preservation of cellulose crystals. It was possible to obtain the average crystallite widths using the scattering patterns, as the cellulose 200 reflection was strongly observable in all three measured samples, which are all presented in Fig. 6d.

For samples TYA 914 and TYA 933, despite the small amount of the sample material, it was possible to generate the average crystallite widths by using the Gaussian fitting method around 200 reflection 


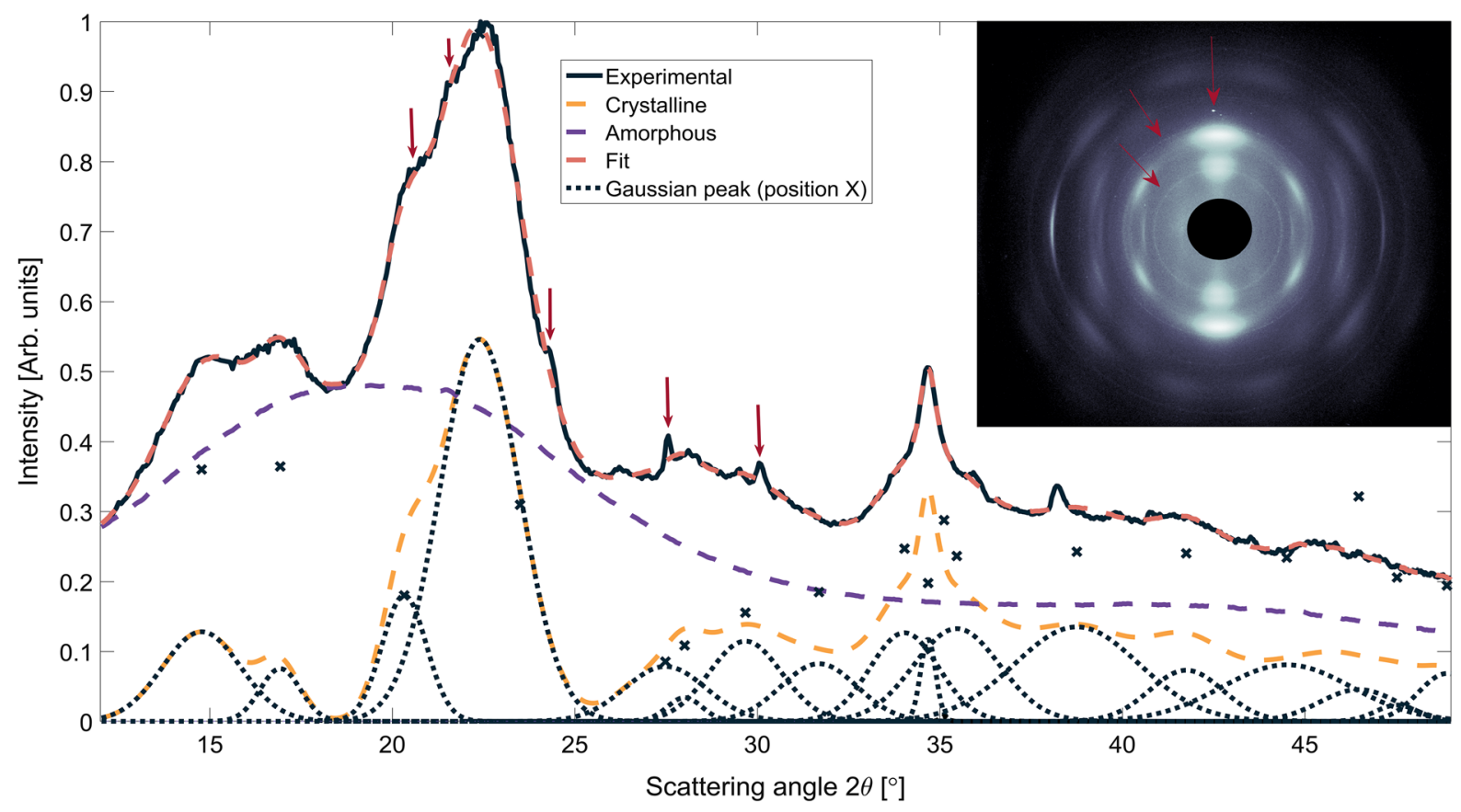

Fig. 4 The crystallinity fit of the modern reference stinging nettle sample Root $\mathrm{C}$, with the $2 \mathrm{D}$ scattering image of the same sample. The data used in the crystallinity analysis has been integrated from the $180^{\circ}$-wide sector around the upmost 200 reflection of cellulose. The crystallite deposits are marked with red arrows. As can be detected here, the crystallinity analysis considers only the cellulose reflections, as indicated with a black dotted line (i.e., the obtained result is the amount of crystalline cellulose among the whole sample)

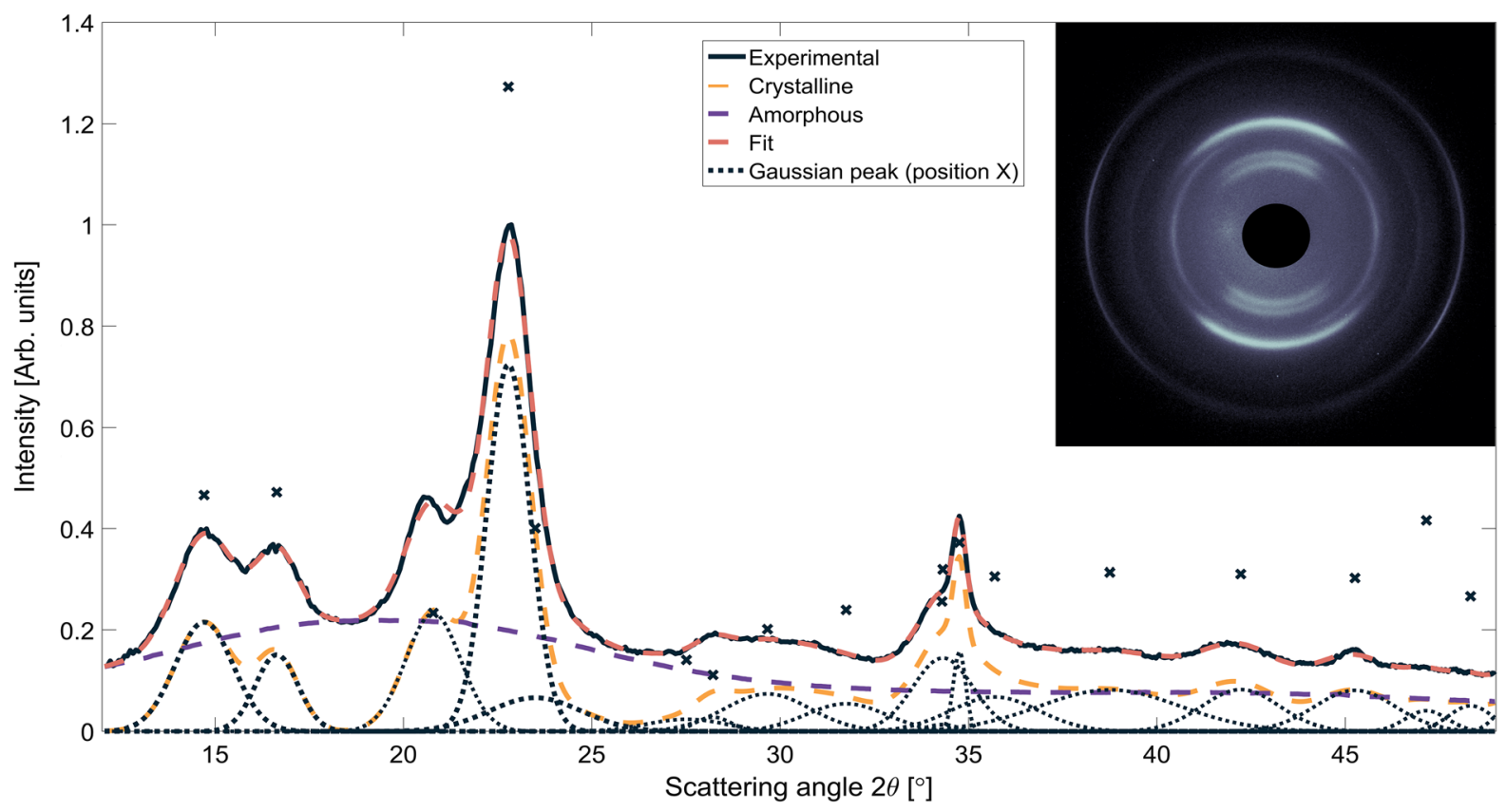

Fig. 5 The crystallinity fit of the ethnographic nettle sample $85 \mathrm{~d}$, with the $2 \mathrm{D}$ scattering image of the same sample. The data used in the crystallinity analysis has been integrated from the $180^{\circ}$-wide sector around the upmost 200 reflection of cellulose 

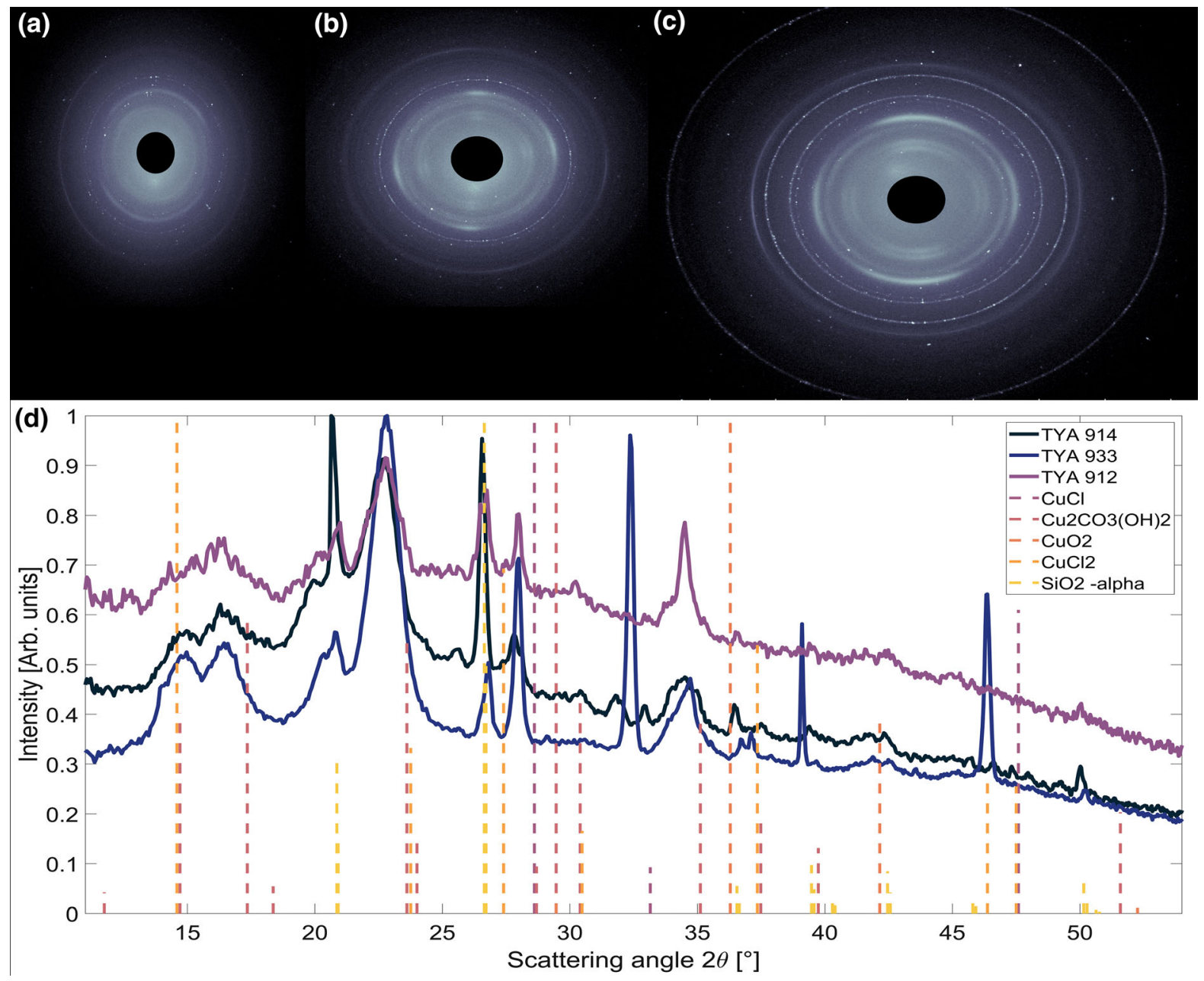

Fig. 6 The 2D scattering images of Ravattula samples. a 2D image of sample TYA 912, b 2D image of sample TYA 914, c scattering image of the sample TYA 933. This sample was in the best condition, as the diffraction maxima for the cellulose are

(described in the Methods section). Only for the sample TYA 912, was the average crystallite width manually estimated by using the Scherrer equation, as the fitting of the Gaussian peaks did not produce reliable results due to low scattering intensities observed (see Fig. 6d). Thus, the error margin for this result is different (larger) from the other two.

\section{Discussion}

Samples consisting of modern, ethnographic, and archaeological fibres were measured using WAXS to determine the average cellulose crystallite width and clearly visible. In $\mathbf{d}$ the most common $\mathrm{Cu}$-compounds and quartz $\left(\mathrm{SiO}_{2}\right)$ responsible for mineralization are mapped with the integrated intensities of each sample

relative crystallinity index for the fibre samples. Transmission and polarization light microscopies were also used to reveal the individual and crosssectional microscale structural features as well as the fibrillar orientation (S/Z-twist) of the chosen ethnographical fibre samples, which represent each of the bast fibre types in this study.

\section{Microscopy studies}

The problems inherent to microscopy method-based identification of bast fibres have been discussed widely: see Suomela et al. 2018, 2020; Haugan and Holst, 2014; Lukesova and Holst 2020. There are 
interpretation issues in longitudinal, cross-sectional as well as in the modified Herzog test images.

In this study, we were not able to detect calcium oxalate crystals in any of the studied samples using PLM. Utilizing the absence or presence of calcium oxalate crystals in the fibre surrounding tissues as a conforming identification feature is also challenging, since if the studied fibres are old or have been thoroughly processed it is highly likely that the crystal-containing tissues may no longer be present. As mentioned by Bergfjord and Holst (2010), in the case of archaeological samples the crystals may be in such a fragmented state that they are no longer visible or identifiable. Thus, plasma-ashing and further analysis with SEM have been suggested (Jakes and Mitchell 1996).

However, SEM and plasma-ashing are destructive methods, which in general makes them less desirable to be used on valuable archaeologic samples. As a non-destructive method, XRD offers a way to study nanosized mineral crystallites, especially if the weight fraction of the mineral among the sample is high enough.

Based on the literature, it can also be hypothesized that the cellulose-formed crystalline structures are the most intact parts of the archaeological plant samples (Atalla and VanderHart 1984; Hearle et al. 1998; Han et al. 2020). Thus, XRD offers an important additional characterization tool in addition to light microscopy methods.

WAXS results on the modern fibres

Based on the WAXS results, the average crystallite widths among the modern fibres varied from 3.4 to $4.8 \mathrm{~nm}$. It should be noted that the values of the crystallite widths varied significantly within the same plant species. This variation is most likely explained by the natural variation of the growth within biological systems.

For flax and hemp, the obtained average crystallite widths are very similar compared to the values acquired in earlier XRD studies: values of around $4.5 \mathrm{~nm}$ (Duchemin et al. 2012) and $3.9 \mathrm{~nm}$ (Leppänen et al. 2009) were obtained for flax fibres, and $4.8 \mathrm{~nm}$ (Virtanen et al. 2012) for hemp, (all of the values were analysed from the cellulose 200 reflection).

In the case of mean MFA, the obtained values ranged from $8^{\circ}$ to $19^{\circ}$ within all the studied modern fibres. For flax and hemp, the obtained MFA values, $8-12^{\circ}$ and $13-14^{\circ}$ respectively, are similar to the reported values of $8-11^{\circ}$ in (Bourmaud et al. 2013; Astley and Donald 2001; Placet et al. 2011).

No earlier data on the average crystallite widths or MFAs in the case of stinging nettle could be found in the literature. Based on the good agreement between our data and earlier results on the average crystallite widths and MFA of flax and hemp, the obtained values for stinging nettle are reliable and convincing.

In the case of relative crystallinity in modern flax and hemp fibres, higher and similar kind of values have been obtained in earlier studies (Duchemin et al. 2012; Thygesen et al. 2005). In the work by Thygesen et al. (2005), the crystallinity values were determined by using a corresponding analysis method (amorphous standard method) and are very similar with the crystallinity values obtained for the ethnographic bast fibres in this study. Also Duchemin et al. (2012) used a corresponding peak fitting method, and the values obtained by that for raw and treated flax fibres are similar with the values obtained for the modern flax fibres of this study.

A higher crystallinity value was obtained for stinging nettle fibres in the earlier studies of Kumar and Das (2017a), in which the relative crystallinity value was determined to be approximately $66 \%$. However, they used Segal peak height-method (Segal et al. 1959) to obtain the crystallinity values for their fibre samples, and this method has been shown to produce too high crystallinity values compared to other analysis methods (Thygesen et al. 2005; Park et al. 2010; Ahvenainen et al. 2016).

As mentioned in the results section, another interesting feature in all of the measured modern samples of nettle and hemp are the crystallite deposits (other than cellulose) that were observed based on the $2 \mathrm{D}$ scattering patterns. These deposits were revealed by the bright diffraction spots and Debye rings, and were also noted in the integrated scattering intensity curves as sharp peaks (spotted by arrows, Figs. 4 and S1). The single bright spots are caused by individual single crystals. Debye rings are detected when the studied material contains these types of crystals in large quantities, isotropically distributed in all possible orientations (i.e., powder-like) throughout the sample.

Most notably, for all of the measured modern nettle samples, both bright spots and Debye rings were present in all of the scattering patterns. The Debye 
rings are especially of interest in this case, as they suggest that the density and distribution of the crystals responsible for the rings are somewhat constant (with a powder-like distribution) throughout the measured sample. For the hemp samples, only bright spots (arising from single crystals) were observed, as shown in Figure S1. The compounds could potentially be $\mathrm{Ca}$ and Si-based, due to their great abundance in plant material overall (Burchi et al. 2014) (see Figure S3, supplementary).

The properties of these crystal deposits, e.g., their density and amount, based on the relative intensity of their diffraction peaks, are higher in all of the scattering patterns obtained for the nettle samples compared to hemp samples. The crystallite deposits are assumed to be the single crystals or clusters formed of different compounds of calcium carbonates and oxalates (Fengel and Wegener 1983; Webb 1999).

The origin of the calcium oxalate crystals in the studied modern fibres is uncertain as these crystals can form in the plant due to various reasons. The oxalate crystals produced by plants are often located in specialized tissue rather than in the fibre tissue itself (Webb et al. 1999). It is also known that the fungal growth associated with wood and plant fibres can produce calcium oxalate crystals (Schwarze 2007). Part of the modern fibres in this study were retted in a bucket, thus some rot fungi may have been present in the process.

For all of the flax samples, similar clear intensity maxima due to the crystal deposits (excluding crystalline cellulose spectra) were not detected in the scattering patterns. This corresponds to the hypothesis based on earlier PLM results in the literature, that the cellular tissue of flax does not contain observable crystal deposits (Catling and Grayson 1982). However, it must be noted that the absence of these crystals in the case of XRD might be caused by the fact that the relative amount of the crystal compounds is too low to be detected.

WAXS results on the White Karelian ethnographic fibres

The White Karelian fibres of flax, nettle, and hemp show significantly higher crystallite widths $(5.3-7 \mathrm{~nm})$ and crystallinity values (48-68\%) compared to the modern fibres extracted from the same species. In addition, the ethnographic nettle and flax fibres were on the average slightly more isotropic compared to the corresponding modern fibres based on the $O P$ values; however, the differences between the ethnographic samples were high.

One possible explanation for the larger crystallite size and crystallinity compared to those of the modern fibres is the mechanical and/or chemical treatments of the fibres connected to the textile making process, as well as wear and care. Certain chemical compounds, e.g., strong bases or acids, and mechanical processes, i.e., milling, as well as sun light are known to break down the amorphous compounds within plant materials (Hearle et al. 1998, Dadashian et al. 2001; Lionetto et al. 2012; Castro et al. 2011). This can cause the remaining cellulose chains to aggregate, as has been observed previously in the case of much stronger chemical treatments such as kraft and sulphite pulping and acid hydrolysis (Leppänen et al. 2009; Virtanen et al. 2012).

The increase in the relative crystallinity of cellulose in fibres due to alkali treatment has also been observed earlier in nettle (Kumar and Das 2017a) and hemp (Sawpan et al. 2011). In the case of flax, only a slight increase in the crystallinity index and the average crystallite widths due to alkali treatment has been observed (Cao et al. 2012).

However, it should be noted that the culturohistorical materials in this study are from time periods when textiles were produced with craft methods. The fibres were most likely first retted and dried, and afterwards commonly braked and stripped to remove the woody xylem of the plant. In the case of nettle, it is also possible that the xylem was removed already from the fresh plants. In the retting process, the fibres are separated from other plant tissues with the aid of moisture and micro-organisms. When properly done it does not affect the highly crystalline bast fibres, but it does dissolve lignin (Hearle et al. 1998).

Regardless of the techniques used, the fibres have gone through vigorous mechanical processes, both in textile manufacturing and care. We cannot say much about the laundry methods in the Late Bronze Age, but in the nineteenth century it was common to use strongly alkaline base compounds, e.g., potassium carbonate and sodium hydroxide, for washing purposes. Lye was traditionally produced from birch ashes, and laundry would be boiled and pounded in it before being twisted in running water to rinse (Vilkuna 1943). 
Additionally, the studied fibres were most likely exposed to direct sunlight for bleaching purposes. Bast fibres obtain their brownish colour from lignin and traditional practices; ready textiles or cloths were bleached in sunlight with the intention of breaking their lignin structures. In photo-oxidation (TímarBalázsy and Eastop 1998), in addition to lignin dissolution, certain wavelengths of ultraviolet radiation are known to break down the amorphous cellulosic compounds in different plant materials, leading to a higher relative crystallinity for the remaining cellulose (Hearle et al. 1998, Dadashian et al. 2001; Lionetto et al. 2012).

WAXS results on the Ravattula archaeological fibres

The obtained crystallite widths for the Ravattula samples are similar, within the error limits (5.6-6.1 nm), compared to the values obtained for the ethnographic samples 2a, 85d, 48b, and 49a, which might be explained by the fact that the Ravattula fibres were probably extracted from the same species of plants (nettle, hemp, or flax), and treated with roughly similar kinds of treatments.

In addition to the results on crystallite width and relative crystallinity, the $2 \mathrm{D}$ scattering images can also provide information about the possible degradation of the cellulose and the mechanical treatments conducted on the fibre, e.g., the textile fibre twisting. In the case of the native fibres, the azimuthal integral was used to determine the cellulose microfibrillar orientation in the form of the microfibril angle. However, for the Karelian and Ravattula fibres this kind of fibrillar orientation could not be determined similarly, because depending on the bundle sizes of the fibre samples, the cellulose 200 reflection can be broadened in the azimuthal direction due to various factors. One possible explanation for the azimuthal broadening is that the studied fibre material has gone through some sort of fibre twisting-procedure. For the archaeological samples TYA912 and TYA914, the observed reflections in the 90-degree azimuthal periods are connected to the fabrics' structure.

Overall, the ability to observe the cellulose reflections, especially in the samples TYA 912 and TYA 914, shows the low degradation rate of the cellulose within the fibres. This is quite surprising, because there are not many well-preserved archaeological plant-fibre samples from different textiles from eleventh century Finland due to the acidic soil type (Riikonen 2011).

The archaeological samples were associated with metal-containing objects, which has potentially helped the preservation of the fibres. The possible mineralization could be observed from the 2D scattering images, as they have many clear Debye rings, which might arise from the metallic oxides, reasonably from copper-containing compounds (Fig. 6a, b and c). Some of the common compounds $\left(\mathrm{CuCl}, \mathrm{CuCl}_{2}\right.$, $\mathrm{CuO}_{2}$, and $\mathrm{Cu}_{2} \mathrm{CO}_{3}$ ) identified in earlier studies (Reynaud et al. 2020) were present in the integrated scattering curves (see Fig. 6d). It has been observed earlier that close contact with metal items promotes the conservation of textile fibres by preventing microbial activity (Janaway 1987). The corrosion process releases metal ions which impregnate the fibre partially or fully, creating a pseudomorph. In addition to microbial activity, acidic soil, which is common in Finland, degrades cellulose-based fibres through acidbased hydrolysis (Hearle et al. 1998). Therefore, surviving textile finds from Finland are often linked to metal artefacts.

The main reflections of quartz $\left(\mathrm{SiO}_{2}\right.$-alpha) were also observed (Fig. 6d), verifying the presence of soil residuals within the archaeological samples.

In addition, fungal activity within the ancient fibres on their preservation sites can produce compounds of calcium and copper oxalates (Jarosz-Wilkolazka and Gadd 2003). Based on the XRD data, calcium oxalates were not present in the Ravattula fibres, however, fungal degradation could potentially explain the observed copper oxalates.

Moreover, the scattering data from this study on the archaeological samples emphasized the fact that a synchrotron facility is not necessarily needed to study archaeological fibre samples. Crucial information about the ultrastructural properties of these types of fibres can also be obtained by using home laboratory WAXS equipment.

\section{Comparison of the results for all of the fibres}

Based on the results for the cellulose crystallite widths obtained for all the samples, the different bast fibre types (hemp, flax, or nettle) cannot be distinguished from each other. This is in line with the earlier conclusions presented by Müller et al. regarding 
archaeological fibres of the same type: hemp/flax/ ramie (Müller et al. 2004, 2007). They concluded that only cotton fibres could be distinguished indisputably from all the other bast fibres.

In the present study, the average cellulose crystallite widths in the studied historical cotton fibre samples were similar compared to the other historical fibre types studied. So, it could be noted here that the cellulose crystallite widths were determined to be significantly larger for all of the historical/archaeological fibre samples compared to the crystallite widths of recent fibres. As such, this is a highly interesting observation and result.

Even though the cellulose crystallite width does not provide information that can be used in the fibre identification, the whole $2 \mathrm{D}$ scattering pattern provides a potential tool for identification purposes. The scattering patterns of modern nettle fibres had features that were not present in any other studied modern fibres: the Debye rings arising from the powder-like distribution of plant mineral crystals. However, these same features were not present in the ethnographic or archaeologic nettle fibres, suggesting that some of the possible treatments of the textiles have removed these mineral crystal deposits from the fibres.

Based on our observations and the results obtained from the set of studied fibres, the Debye rings could potentially be used as an indication of fibre type and condition. When the Debye rings are present in the 2D WAXS patterns, it is possible to distinguish fibres with the same crystallite widths, i.e., nettle fibres from flax and cotton, as the mineral compounds (possible Si or $\mathrm{Ca}$ compounds) responsible for the rings are only present in nettle. Furthermore, this information could potentially be useful for criminal investigation purposes, as well as for historical research concerning nettle textiles and fibres.

\section{Conclusions}

In this study, modern, ethnographical and archaeological fibre samples of flax, hemp, and nettle were studied using Wide-angle X-ray Scattering (WAXS). The scattering patterns of crystalline cellulose were observed in all of the archaeological fibre samples, thus revealing the presence of crystalline cellulose in significant amounts in all these samples. By using the WAXS data, the ultrastructural features of modern nettle fibres were determined and compared to the corresponding values of flax and hemp, which has not been done previously. The average cellulose crystallite width in the modern nettle fibres was $3.7 \mathrm{~nm}$, which was slightly smaller than the average crystallite widths of flax $(4.4 \mathrm{~nm})$ and hemp $(4.2 \mathrm{~nm})$. However, the variability between the individual fibre samples was of the same scale than the differences between these species.

Interestingly, the cellulose crystallite widths and relative crystallinities were significantly larger in all of the historical and archaeological fibre samples studied, which might correspond to annealing effect. The scattering patterns of the modern nettle fibres revealed the presence of other crystalline compounds, presumably different compounds of $\mathrm{Ca}$ and $\mathrm{Si}$, which were seemingly abundant throughout the measured nettle fibre samples. This observation could potentially be further utilized to identify modern nettle fibres from flax, hemp, and cotton. It can be concluded that the laboratory WAXS results revealed the ultrastructure and state of cellulose structures in the historical and archaeological fibres, and thus further studies regarding different archaeological fibre remnants should be conducted.

Acknowledgments K.S. and M.V. acknowledge the University of Helsinki (3-year research Grant). J.S. acknowledge the Grant from Karjalaisen Kulttuurin Edistämissäätiö. We acknowledge the provision of facilities and technical support by Aalto University at OtaNano Nanomicroscopy Center (Aalto-NMC). We would like to thank Ville Heiskanen from the Botanical Gardens of University of Helsinki, in Kumpula; Jaana Riikonen and Juha Ruohonen from the University of Turku; and Ildikó Lehtinen and Anna-Mari Immonen from the National Museum of Finland.

Authors' contributions MV and KS carried out the scattering experiments. JS carried out the optical microscopy measurements. MV wrote the manuscript with support from JS and KS. All of the authors conceived the original idea.

Funding Open Access funding provided by University of Helsinki including Helsinki University Central Hospital. This study was funded by a University of Helsinki 3-year research Grant.

Data availability Data is available upon request.

Code availability All the custom scripts used in data-analysis are available upon request. 


\section{Declarations}

Conflict of interest The authors declare that they have no competing interests.

Open Access This article is licensed under a Creative Commons Attribution 4.0 International License, which permits use, sharing, adaptation, distribution and reproduction in any medium or format, as long as you give appropriate credit to the original author(s) and the source, provide a link to the Creative Commons licence, and indicate if changes were made. The images or other third party material in this article are included in the article's Creative Commons licence, unless indicated otherwise in a credit line to the material. If material is not included in the article's Creative Commons licence and your intended use is not permitted by statutory regulation or exceeds the permitted use, you will need to obtain permission directly from the copyright holder. To view a copy of this licence, visit http://creativecommons.org/licenses/by/4.0/.

\section{References}

Ahvenainen P, Kontro I, Svedström K (2016) Comparison of sample crystallinity determination methods by X-ray diffraction for challenging cellulose I materials. Cellulose 23(2):1073-1086. https://doi.org/10.1007/s10570-0160881-6

Andersson S, Serimaa R, Paakkari T, Saranpää P, Pesonen E (2003) Crystallinity of wood and the size of cellulose crystallites in Norway spruce (Picea abies). J Wood Sci 49(6):531-537. https://doi.org/10.1007/s10086-003-0518$\mathrm{x}$

Astley OM, Donald AM (2001) A small-angle X-ray scattering study of the effect of hydration on the microstructure of flax fibers. Biomacromol 2(3):672-680. https://doi.org/10. 1021/bm0056431

Atalla RH, Vanderhart DL (1984) Native cellulose: a composite of two distinct crystalline forms. Science 223(4633):283-285. https://doi.org/10.1126/science.223. 4633.283

Bergfjord C, Holst B (2010) A procedure for identifying textile bast fibres using microscopy: flax, nettle/ramie, hemp and jute. Ultramicroscopy 110(9):1192-1197. https://doi.org/ 10.1016/j.ultramic.2010.04.014

Bergfjord C, Mannering U, Frei KM, Gleba M, Scharff AB, Skals I, Heinemeier J, Nosch ML, Holst B (2012) Nettle as a distinct Bronze Age textile plant. Sci Rep 2:664. https:// doi.org/10.1038/srep00664

Bourmaud A, Morvan C, Bouali A, Placet V, Perre P, Baley C (2013) Relationships between micro-fibrillar angle, mechanical properties and biochemical composition of flax fibers. Ind Crops Prod 44:343-351. https://doi.org/10. 1016/j.indcrop.2012.11.031

Burchi G, Bauchan GR, Murphy C, Roh MS (2014) Characterisation of calcium crystals in Abelia spp. using X-ray diffraction and electron microscopy. J Hortic Sci
89(1):61-68. https://doi.org/10.1080/14620316.2014. 11513049

Cao Y, Chan F, Chui YH, Xiao H (2012) Characterization of flax fibres modified by alkaline, enzyme, and steam-heat treatments. BioResources 7(3):4109-4121

Castro K, Princi E, Proietti N, Manso M, Capitani D, Vicini S, Madariaga JM, De Carvalho ML (2011) Assessment of the weathering effects on cellulose-based materials through a multianalytical approach. Nucl Instrum Methods Phys Res B 269(12):1401-1410. https://doi.org/10.1016/j.nimb. 2011.03.027

Catling D, Grayson J (1982) Introduction. In: Identification of vegetable fibres. Springer, Dordrecht. https://doi.org/10. 1007/978-94-011-8070-2_1

Chen HL, Jakes KA, Foreman DW (1998) Preservation of archaeological textiles through fibre mineralization. J Archaeol Sci 25(10):1015-1021. https://doi.org/10.1006/ jasc. 1997.0286

Dadashian F, Wilding MA (2001) Photodegradation of lyocell fibers through exposure to simulated sunlight. Text Res J 71(1):7-14. https://doi.org/10.1177/004051750107100102

Debnath S (2015) Great potential of stinging nettle for sustainable textile and fashion. In: Handbook of sustainable luxury textiles and fashion (pp. 43-57). Springer, Singapore. https://doi.org/10.1007/978-981-287-633-1_3

Deedrick DW (2000). Hairs, fibres, crime, and evidence: Part 2, fibre evidence. US Department of Justice, Federal Bureau of Investigation

Duchemin B, Thuault A, Vicente A, Rigaud B, Fernandez C, Eve S (2012) Ultrastructure of cellulose crystallites in flax textile fibres. Cellulose 19(6):1837-1854. https://doi.org/ 10.1007/s10570-012-9786-1

Fengel D, Wegener G (Eds.) (1983) Wood: chemistry, ultrastructure, reactions. Walter de Gruyter. https://doi.org/10. 1515/9783110839654

Geijer A (1979) A history of textile art: a selective account. Sotheby Parke Bernet, London

Good I (2001) Archaeological textiles: a review of current research. Annu Rev Anthropol 30(1):209-226. https://doi. org/10.1146/annurev.anthro.30.1.209

Han L, Tian X, Keplinger T, Zhou H, Li R, Svedström K, Burgert I, Yin Y, Guo J (2020) Even visually intact cell walls in waterlogged archaeological wood are chemically deteriorated and mechanically fragile: a case of a 170-yearold shipwreck. Molecules 25(5):1113. https://doi.org/10. 3390/molecules25051113

Haugan E, Holst B (2013) Determining the fibrillar orientation of bast fibres with polarized light microscopy: the modified Herzog test (red plate test) explained. J Microsc 252(2):159-168. https://doi.org/10.1111/jmi.12079

Haugan E, Holst B (2014) Flax look-alikes: pitfalls of ancient plant fibre identification. Archaeometry 56(6):951-960. https://doi.org/10.1111/arcm.12054

Hearle JW, Lomas B, Cooke WD (1998) Atlas of fibre fracture and damage to textiles, Part VIII - Fibre Archaelogy and Textile Conservation. Elsevier

Jakes K, Mitchell J (1996) Cold plasma ashing preparation of plant phytoliths and their examination with scanning electron microscopy and energy dispersive analysis of X-rays. J Archaeol Sci 23(1):149-156. https://doi.org/10. 1006/jasc.1996.0012 
Janaway RC (1987) The preservation of organic materials in association with metal artefacts deposited in inhumation graves. In Death, decay and reconstruction: approaches to archaeology and forensic science (pp. 127-148). Manchester: Manchester University Press.

Jarosz-Wilkolazka A, Gadd GM (2003) Oxalate production by wood-rotting fungi growing in toxic metal-amended medium. Chemosphere 52(3):541-547. https://doi.org/10. 1016/S0045-6535(03)00235-2

Kuczyński W, Żywucki B, Małecki J (2002) Determination of orientational order parameter in various liquid-crystalline phases. Mol Cryst Liq Cryst 381(1):1-19. https://doi.org/ 10.1080/713738745

Kumar N, Das D (2017a) Alkali treatment on nettle fibres: Part I: investigation of chemical, structural, physical, and mechanical characteristics of alkali-treated nettle fibres. J Text Inst 108(8):1461-1467. https://doi.org/10.1080/ 00405000.2016 .1257346

Kumar N, Das D (2017b) Fibrous biocomposites from nettle (Girardinia diversifolia) and poly (lactic acid) fibers for automotive dashboard panel application. Compos B Eng 130:54-63. https://doi.org/10.1016/j.compositesb.2017. 07.059

Lanzilao G, Goswami P, Blackburn RS (2016) Study of the morphological characteristics and physical properties of Himalayan giant nettle (Girardinia diversifolia L.) fibre in comparison with European nettle (Urtica dioica L.) fibre. Mater Lett 181:200-203. https://doi.org/10.1016/j.matlet. 2016.06.044

Leppänen K, Andersson S, Torkkeli M, Knaapila M, Kotelnikova N, Serimaa R (2009) Structure of cellulose and microcrystalline cellulose from various wood species, cotton and flax studied by X-ray scattering. Cellulose 16(6):999-1015. https://doi.org/10.1007/s10570-0099298-9

Lionetto F, Del Sole R, Cannoletta D, Vasapollo G, Maffezzoli A (2012) Monitoring wood degradation during weathering by cellulose crystallinity. Materials 5(10):1910-1922. https://doi.org/10.3390/ma5101910

Lukesova H, Holst B (2020) Is cross-section shape a distinct feature in plant fibre identification? Archaeometry. https:// doi.org/10.1111/arcm.12604

Markova I (2019) Textile fibre microscopy: a practical approach. Wiley. https://doi.org/10.1002/9781119320029

Müller M, Murphy B, Burghammer M, Riekel C, Roberts M, Papiz M et al (2004) Identification of ancient textile fibres from Khirbet Qumran caves using synchrotron radiation microbeam diffraction. Spectrochim Acta B: at Spectrosc 59(10-11):1669-1674. https://doi.org/10.1016/j.sab.2004. 07.018

Müller M, Murphy B, Burghammer M, Snigireva I, Riekel C, Gunneweg J, Pantos E (2006) Identification of single archaeological textile fibres from the cave of letters using synchrotron radiation microbeam diffraction and microfluorescence. Appl Phys A 83(2):183-188. https:// doi.org/10.1007/s00339-006-3516-1

Müller M, Murphy B, Burghammer M, Riekel C, Pantos E, Gunneweg J (2007) Ageing of native cellulose fibres under archaeological conditions: textiles from the Dead Sea region studied using synchrotron X-Ray microdiffraction.
Appl Phys A 89(4):877-881. https://doi.org/10.1007/ s00339-007-4219-y

Nayak RK, Padhye R, Fergusson S (2012) Identification of natural textile fibres. In: Kozlowski RM (ed) Handbook of natural fibres, Woodhead Publishing Series in Textiles, vol 1. Woodhead, Oxford, pp 314-344. https://doi.org/10. 1016/c2013-0-17333-3

Nishiyama Y, Langan P, Chanzy H (2002) Crystal structure and hydrogen-bonding system in cellulose $\mathrm{I} \beta$ from synchrotron $\mathrm{X}$-ray and neutron fiber diffraction. JACS 124(31):9074-9082. https://doi.org/10.1021/ja0257319

Park S, Baker JO, Himmel ME, Parilla PA, Johnson DK (2010) Cellulose crystallinity index: measurement techniques and their impact on interpreting cellulase performance. Biotechnol Biofuelss 3(1):10. https://doi.org/10.1186/ 1754-6834-3-10

Placet V, Bouali A, Perré P (2011) The possible role of microfibril angle of Hemp fibre during fatigue tests and its determination using Wide-Angle X-ray diffraction. Mater Tech 99(6):683-689. https://doi.org/10.1051/mattech/ 2011120

Ramamoorthy SK, Skrifvars M, Persson A (2015) A review of natural fibres used in biocomposites: plant, animal and regenerated cellulose fibres. Polym Rev 55(1):107-162. https://doi.org/10.1080/15583724.2014.971124

Reiterer A, Lichtenegger H, Tschegg S, Fratzl P (1999) Experimental evidence for a mechanical function of the cellulose microfibril angle in wood cell walls. Philos Mag A 79(9):2173-2184. https://doi.org/10.1080/ 01418619908210415

Reynaud C, Thoury M, Dazzi A, Latour G, Scheel M, Li J, Thomas A, Moulhérat C, Didier A, Bertrand L (2020) Inplace molecular preservation of cellulose in 5000-year-old archaeological textiles. PNAS 117(33):19670-19676. https://doi.org/10.1073/pnas.2004139117

Riikonen J (2011) White linen: cloth of luxury. In: Harjula J, Helamaa M, Haarala J (eds) Times, things \& places: 36 essays for Jussi-Pekka Taavitsainen, 198-221. Masku: J.P. Taavitsainen Festschrift Committee

Ruohonen J (2017) Ristimäki in Ravattula: on the remains of the oldest known church in Finland. In: Harjula \& Hukantaival (eds) New visits to old churches: sacred monuments and practices in the Baltic Sea Region, Cambridge Scholars Publishing, pp 46-60

Sanjay MR, Siengchin S, Parameswaranpillai J, Jawaid M, Pruncu CI, Khan A (2019) A comprehensive review of techniques for natural fibers as reinforcement in composites: Preparation, processing and characterization. Carbohydr Polym 207:108-121. https://doi.org/10.1016/j. carbpol.2018.11.083

Sarén M-P, Serimaa R, Andersson S, Saranpää P, Keckes J, Fratzl P (2004) Effect of growth rate on mean microfibril angle and cross-sectional shape of tracheids of Norway spruce. Trees 18(3):354-362. https://doi.org/10.1007/ s00468-003-0313-8

Sawpan MA, Pickering KL, Fernyhough A (2011) Effect of various chemical treatments on the fibre structure and tensile properties of industrial hemp fibres. Compos Part A Appl Sci Manuf 42(8):888-895. https://doi.org/10.1016/j. compositesa.2011.03.008 
Schwarze FW (2007) Wood decay under the microscope. Fungal Biol Rev 21(4):133-170. https://doi.org/10.1016/j.fbr. 2007.09.001

Segal LGJMA, Creely JJ, Martin AE Jr, Conrad CM (1959) An empirical method for estimating the degree of crystallinity of native cellulose using the X-ray diffractometer. Text Res J 29(10):786-794. https://doi.org/10.1177/ 004051755902901003

Sfiligoj Smole S, Hribernik S, Stana Kleinschek K, Kreže T (2013) Plant fibres for textile and technical applications. Adv Agrophys Res. https://doi.org/10.5772/52372

Suomela JA, Vajanto K, Räisänen R (2018) Seeking nettle textiles-utilizing a combination of microscopic methods for fibre identification. Stud Conserv 63(7):412-422. https://doi.org/10.1080/00393630.2017.1410956

Suomela JA, Vajanto K, Räisänen R (2020) Examining the White Karelian Textile tradition of the late nineteenth century-focus on plant fibres. Textile 18(3):298-324. https://doi.org/10.1080/14759756.2019.1699365

Suomela J, Suhonen H, Räisänen R, Vajanto K (2022) Identifying late iron age textile plant fibre materials with X-ray methods - a study on finds from Ravattula Ristimäki (Kaarina, Finland). Archaeol Anthropol Sci, Accepted 10.1.2022

Svedström K, Bjurhager I, Kallonen A, Peura M, Serimaa R (2012) Structure of oak wood from the Swedish warship Vasa revealed by X-ray scattering and microtomography. Holzforschung 66(3):355-363. https://doi.org/10.1515/hf. 2011.157

Thygesen A, Oddershede J, Lilholt H, Thomsen AB, Ståhl K (2005) On the determination of crystallinity and cellulose content in plant fibres. Cellulose 12(6):563. https://doi.org/ 10.1007/s10570-005-9001-8

Tímár-Balázsy Á, Eastop D (1998) Chemical principles of textile conservation. Butterworth-Heinamann, Oxford. https://doi.org/10.4324/9780080501048-25

Vajanto K (2014) Finnish shipwreck textiles from the 13th-18th centuries AD. Monographs of the Archaeological Society of Finland 3: focus on archaeological textiles: Multidisclip Approach 116-131

Viju S, Thilagavathi G (2020) Characterization of surface modified nettle fibers for composite reinforcement. J Nat Fibers. https://doi.org/10.1080/15440478.2020.1788491

Vilkuna K (1943) Isien työt $1-$ Veden ja maan vilja. Otava, Helsinki

Virtanen T, Svedström K, Andersson S, Tervala L, Torkkeli M, Knaapila M, Kotelnikova N, Maunu SL, Serimaa R (2012) A physico-chemical characterisation of new raw materials for microcrystalline cellulose manufacturing. Cellulose 19(1):219-235. https://doi.org/10.1007/s10570-011-96366

Wada M, Okano T, Sugiyama J (1997) Synchrotron-radiated $\mathrm{X}$-ray and neutron diffraction study of native cellulose. Cellulose 4(3):221-232. https://doi.org/10.1023/A: 1018435806488

Webb MA (1999) Cell-mediated crystallization of calcium oxalate in plants. Plant Cell 11(4):751-761

Publisher's Note Springer Nature remains neutral with regard to jurisdictional claims in published maps and institutional affiliations. 